\section{A CASE OF ANTEVERTED WANDERING LIVER.}

BY RAYMOND CRAWFURD, M.A., M.D. OxON., M.R.C.P. LOND.,

ASSISTANT PHYSJCIAN TO THE ROYAL FREE HOSPITAL AYD TO THF vicTorid Hospital FOR CHILDREN, CHELSEA.

IN his "Treatise on Diseases of the Liver" the late Dr. George Ilarley wrote: "There is yet another possible source of error, though from its extreme rarity an error is unlikely to be committed. But, as the mistake is said to have once occurred, and it is quite possible it may occur again, it is but right that I should call attention to itnamely, the possibility of mistaking an anteverted small liver for an enlarged one." In the case that I record below, history has repeated itself to my own discomfiture. I have appropriated the term "anteverted" rather than "moveable" liver because the condition was ratber one of axial rotation than of excessive mobility of the organ. The case will be seen to be one of peculiar interest, both because of the symptiom complex and its post-mortem corroboration, and of the histological condition of the liver.

The patient, a woman, aged sixty-five years, attended the out-patient department of the Royal Free Hospital on May, 12th, 1897, and every subsequent week till Jaly 7th, when she was admitted to the wards under my care. The following was the history of the patient when first seen. She complained of progressive weakness and pain all over, and there was yellowness and itching of the skin. The patient was married, but had had only one child, which was stillborn at full term; there was no history of parental tubercle or carcinoma; she had had twelve brothers and sisters, of whom only two were living, one brother having died from phthisis and the rest from unknown causes. When quite a child she had suffered with generalised dropsy she did not know the cause of it but it was not associated with scarlet fever which she also had in childhood. The patient had had a left inguinal hernia for twenty-three years and bæmorrhoids for some years. Six months previously jaundice had set in insidionsly with some abdominal pain but not of any severity. At the time she suffered a good deal from vomiting of a paroxysmal type, and was obliged to call in a medical practitioner, who ordered her to bed. In the course of a week or two the attacks of vomiting gradnally subsided, but she lost flesh steadily. The jaundice became more intense; the appetite was completely lost; solids caused immediate nausea, so that only liquids were taken; since tre illness commenced she had taken a quartern of gin dally, but prior to that she had never exceeded one and $a$ half pints of ale a day. The bowels were at first constipated and the motions whitish and foul-smelling.

Oa May 12th she attended the ont-patient department and was found to be in the following condition. There was intense obstructive jaundice of four months' duration. Liver dulness commenced at the sixth rib in the right mammary line and at the eighth rib in the mid-axillary line, and the edge could be felt at the level of the umbilicus. The enlargement appeared to be entirely of the right lobe; the surface was smooth; the edge was very hard and blunt; no nodules could be felt ; and there was no pain on pressure. The gallbladder could be clearly felt distended and projecting from beneath the edge of the liver about three inches to the right of the ambilicus.

Cancer of the liver was suspected, although no nodules could be felt and there was no marked tenderness or piin, but a primary seat coulc not be detected in the uterus or bowel, nor were there any indications of cancer of the stomach or bead of the pancreas, so that the distended gallbladder was fixed upon as the possible primary focus from which the disease had spread directly to the under-surface of the liver. The lungs were emphysematous and dry J honchi were heard here and there on each side of the chest. For the next two months nothing special occurred beyond gradual emaciation and asthenia, with occasional attacks of acute pain in the right hypochondrium of a colicky nature. The constipation was relieved by a daily morning dose of mistura alba

On admission to the wards on July 7 th the patient was fonnd to be much emaciated, and the conjunctiva and the skin were a deep yellowish green in colour. The patient expressed herself as much more comfortable in bed than when getting about; she lay chiefly on her back, but could lie in any position. There were complete anorexia and frequent nausea; the mouth was very dry and there was a constantly unpleasant taste; the tongue was coated with a dry and dirty whitish far; there was no pain and the patient rarely vomited after food. A good deal of troublesome flatulence was present ; the bowels were now regular, but the motions were loose and white; the stomach was not distended, and no tumour could be felt there. The superficial abdominal veins on each side were enlarged ; there was obvious fulness of the right bypocbondriac and lumbar regions, extending into the epigastrium, but the abdomen as a whole was

Fia. 1.

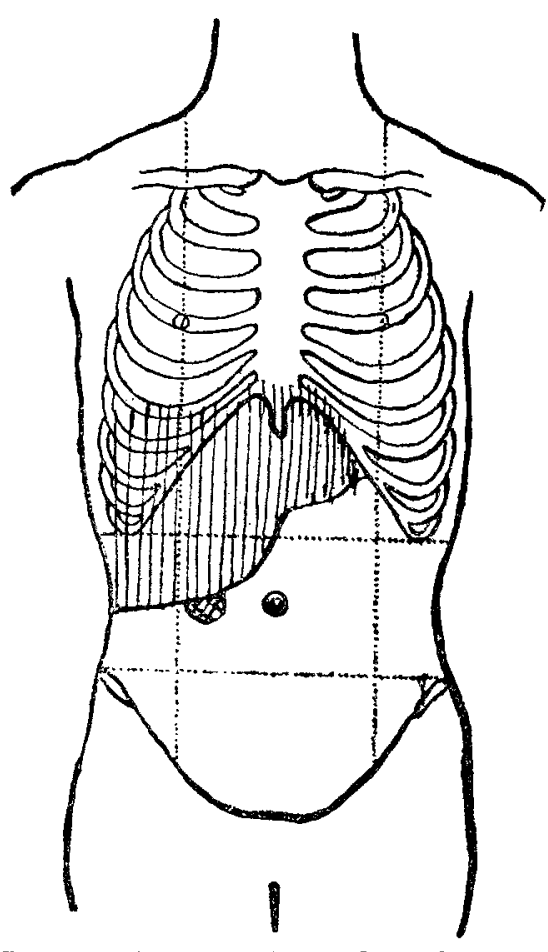

Representing condition on May 12th, 1897.

swagged over to the left, the intestines being apparently pushed en masse to this side; there was a large left inguinal hernia. The abdominal walls were very thin and flaccid, and the recti were separated; there was some tenderness on the right side of the epigastrium ; a considerable tumour was felt reaching as low as the right iliac region, and entending upwards beneath the ribs. 'The percussion note was dull from the seventh rib in the mammary line to the lower edge of the tumour, which was felt to be the right lobe of the liver; its features have been already described. The gallbladder could be felt clearly midway between the pubes and the umbilicus, a little to the right of the median line; the point of the finger conld be readily inserted between the gall-bladder and the edge of the liver. The spleen cculd not be felt and was not enlarged to percussion. There was slight œdema of both legs, and there were some purpuric spots on the shins. The catamenia had ceased at the age of fifty-two years; for three months there had been a yellowish, quite odourless, discharge from the vagina On examination per vaginam the cervix uteri was found to be atropbied; no induration was prestnt the fundus could not be felt, and the fornices were free. Per rectum no tumour was felt, bat external bæmorrhoids were present. The urine was deep greenish in colour, of specific gravity 1008 , and faintly acid; it contained no albumin, sugar, or blood, but bile pigment was abundant. The arteries were slightly thickened; the heart's impulse was feeble, but it was felt in the fifth interspace, just internal to the nipple; and the cardiac area and heart sounds were normal. The pulse was 80 . The patient had had a cough for many years on and off; it was especially troublesome in the morning; the expectoration was yellowish and frothy. She was short of breath and her voice was hoarse and weak; the chest wall was much wasted, deeply jaundiced, and mored but little in respiration, thongh the movements were equal on each side. Behind, the lower ribs on the right side were much more prominent than those on the left; vocal fremitus was normal; there were a few palpable rhonchi. There was general resonance on percussion; the breath sounds were rather harsher over the right side than the left; expiry was 
prolonged all over ; there were generalised rhonchi, and the respirations were 16. On July 13th there was a good deal of dragging pain in the lower part of the back and also over the epigastrium and left hypochondriac region, which made the patient feel very faint. On the 16th there was similar pain confined to the right side of the abdomen. On the 2Jth, for the first time, the left lobe of the liver could be felt distinctly increased in size; the right lobe was steadily descending; the gall-bladder seemed more solid and fluctuation was not now so readily obtained; the abdomen measured $31 \frac{1}{4}$ in. at the levtl of the navel. On the 27ch it was noted that during the previous three days the liver had distinctly descended as much as two or three inches, and the right lobe was then only an inch above the midd!e of Poupart's ligament; the whole edge of both lobes could be plainly felt, and there was a small amount of moveable fluid in the lanks. The intestines were thrust still further over to the left side; the liver was painful on pressure; so was the gall-bladder; the edge could not be pushed up, and the abdomen was $30_{4}^{3} \mathrm{in}$. at the umbilicus.

FIG. 2.

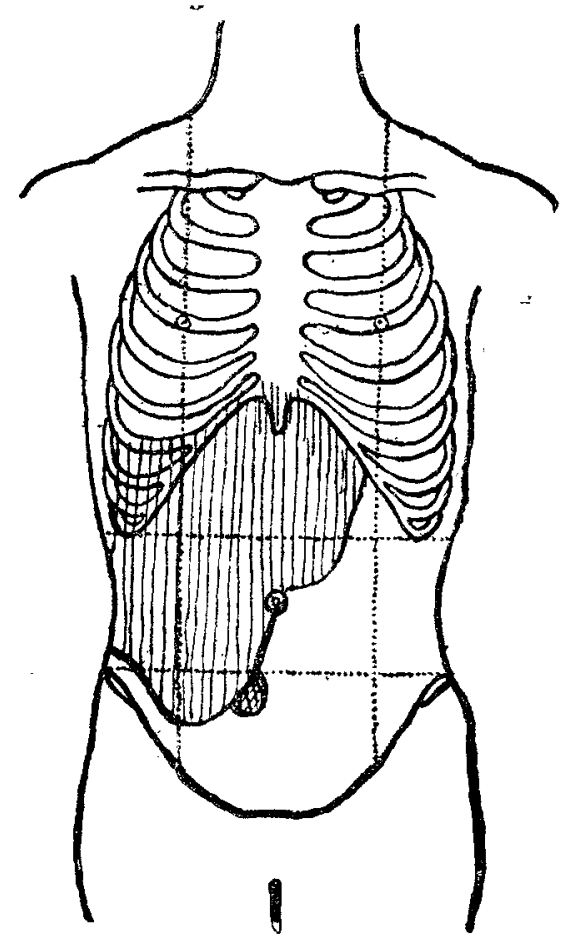

Representing condition on July 27th, 1897.

On the $30 \mathrm{th}$ there was no more pain, but the irritation of the shin was renewed; rhonchi were present all over the chest behind. The entry of air was not so free at the left base as at the right. The bowels opened regularly. The urine showed a trace of albumin but nc casts. and the ascites was increasing. By Aug. 5th the patient had become more and more feeble and emaciated. There were several purpuric spots on the legs; the temperature had undergone slight remissions for two or three days. Until the 16th there was steady progress of the weakness and emaciation; the patient complained of drowsiness and chilliness, but there was no pain. The abdomen then measured $32 \frac{1}{2}$ in. at the umbilicus; there was no further enlargement of the liver and no tenderbess; the jaundice was deeper. By the 19th diarrhoea bad set in and more bronchitis; the patient was given a starch and opium enema, which diminished the diarrhoea, and also sone carbonate of ammonia and tincture of squills. By Sept. 3rd no mate! ial change bad been noted, but there was a steady decline of strength; there was more diarrbcea; the whole abdomen was very tender, and the patient could not bear the lightest touch. On the $10 \mathrm{th}$ there was an increase in the diarrhcea; the abdomen was more distended; much bronchitis was present, and the patient was gradually sinking. Death took place on Bept. 11 th.

Necropsy. - A post-mortem examination wrs made eight hours after death. The body was much wasted, the abdomen was distended, the ssin and mucous membranes were deeply pigmented. On opening the thorax the left pleural cavity was found to be obliterated behind by old adhesions; a small quantity of serous fluid was digcorered in the right pleura; the right lung containet a caseous nociule at the apex, but ctherwise it was normal, and the bronchial secretion was bile-stained. In the heart the muscle was pale, flabby, and bile-stained, but the cavities and valves were normal. The abdomen was fall of bile-stained serum, the intestines were driven over to. the left side, the liver was completely anteverted and lying on the intestines in the long axis of the abdomen, the lower edge of the right lobe was not much more than a hand's breadth below the costal margin in the right mammary line, and the liver surface was smooth, and its consistence firm, especially at the $\epsilon$ dges. The weight of the organ was $54 \mathrm{cz}$. and its transverse measurement was $10 \mathrm{in.}$ On section the liver was dripping with bile and deeply bile-stained, and the bile ducts within the liver were distended to the size of the lictle finger and full of thick, green bile. The liver was not specially mobile apart from the other viscera; there was no mesohepar and no apparent elongation of the ligaments. The gall-bladder was hypertrophied and much distended with deep-green bile, some of which was semi-solid, and its peritoneal sheath was thick and opaque. The cystic duct was distended, the hepatic duct was markedly so, and the common duct was not distended; the walls of the duct were normal ; bile papilla was patent. The bile could be expressed readily from the gall.bladder into the intestine and a good-sized catheter could be passed throughout the ducts. There were no glands in the portal fissure or stones or adhesive bands. The spleen was slightly enlarged and firm, and adherent to the parietes by partially organised adbesions; there had been lecent perisplenitis also. The stomach was not dilated. The pancreas was normal. Neither kidney was moveable.

Microscopical examination of the liver showed $\epsilon$ xtensive dilatation of the bile ducts, and around these widespreading pericholangeal fibrosis. The greater part of the liver was markedly odematous - a condition that could also be seen in the cirrhotic areas around the bile ducts. The atrophy of the liver cells was fairly uniform throughout the liver and not specially marked close around the distended bile ducts. Here and there could be seen a suspicicn of unicellular cirrhosis, but only in a few small and isolated areas; there were no pseudo-bile canaliculi and no intra-hepatjc calculi could be seen. For the microscopical secti:ns, all of whick were admirably cut and stain $\epsilon$, I am indebted to $M$ is $s$ Webb, M.B. Lond., curatrix of the museum of the Royal Free Hospital.

Remarks - In searching through the literature of hepatoptosis I find two cases only in which the signs were almost identical with those in the above case but in each of these there was a great difference in the symptoms. The one is recorded by $P \in t \in \mathrm{rs}^{1}{ }^{1}$ in which the liver was found resting on its under surface with its long diameter parallel to the median line of the body, the right lobe being lowest and on a level with the anterior superior spinous process ; and the other by Griffiths, ${ }^{2}$ in which, in a man, aged fifty-four years, "the liver dulness extended from two fingers' breadth below the nipple to the crest of the ileum and partly into the iliac fossa, eight inches. in the perpendicular right nipple line." Yet at the necropsy the organ was found to measure only ten inches transversely and eight inches in the antero-posterior direction, weighing fifty-six ounces. This unusual state of affairs, he says, was due to "the liver Jying on its under surface in the lombar region, the anterior edge of the right lobe being down in the iliac fossa. The organ appeared as if it had been partly rotated upon its own transverse axis-or, in other words, anteverted-so as to allow its upper surface to be felt throvgh the abdominal wall below the ribs."

This was precisely the condition in life in the above case, the liver at first being anteverted and also rotated from right to left so as to bring the right lobe below. In this way the vertical upper limit of liver dulness remained ucchanged until the liver descended en masse, and it was possible then to feel the edge of the left lobe of the liver. The postmortem findings suggest that the jaundice that persisted from the very outset must have been due to kinking or torsion of the bile duct-indeed, bearing in mind the limits of distension of the ducts outside the liver, the evidence is almost demonstrative, the site of the kink being at the commencement of the common duct. In the absence of any severe attack of colic the constricting process would presumably have been a slow one. With the final descent of the liver on came ascites, which may reasonably be 
referred to kinking of the portal vein. The cedema of the legs may similarly bave been due to a partial occlusion of the inferior vena cava from traction Another point of interest is the position of the liver after death, in no way corresponding to the ante-mortem demarcation. The same circumstances led Wickbam Legg ${ }^{3}$ to disbelieve the existence of true hepatoptosis, except in mistaken diagnosis. Packard, ${ }^{4}$ however, records a case in which before death the liver edge reached from nine to ten centimetres below the costal margin and post mortem it was in its normal position under the diaphragm and almost hidden by the costal cartilages. Landan ${ }^{5}$ likewise points out that the diagnosis of hepatoptosis has not been conclusively established by necropsy. Yet the condition is only to be expected with the ascent of the diaphragm that occurs at death; and the reality of hepatoptosis has been ccnfirmed both by abdominal section and post-mortem observation. It is difficult to say whetber the descent of the liver was, as Glenard holds, merely a terminal incident of a general enteroptosis. No such condition was discerned either before or after death, but the readiness with which the intestines waridered into the left flank, and the existence of an inguinal hernia on the left side suggest such a possibility; also the liver, though so extensively displaced, was very slightly mobile apart from the intestines. On the other hand the stomach was normally situated and there was no associated mobility of the kidneys. Glenard mentions albuminuria and leucorrhea as conditions associated with hepatoptosis, and both were present in this case, but the albuminuria may well have been a secondary effect of the jaundice, and though leucorrhea may be a sequel of enteroptosis it can hardly be a direct sequel of hepatoptosis.

In any given case it is difficult to assign the exact causation to a moveable liver: in this case the abdominal walls were remarkably pendulous. Landau regards this as the main cause of hepatoptosis, and Grabam ${ }^{\circ}$ found a distinct relation to frequent pregnancy at short intervals, nearly all cases of non-traumatic origin occurring in women. The intestives act as a cushion which supports the liver in its position nnder the diaphragm by the even pressure of healthy abdominal muscles. But obviously flaccid abdominal valls do not alone produce hepatoptosis, as the former condition is very common, the latter very rare. Graham showed in the cadaver that, in the ordinary way, the ligaments were strong enough to carry the whole weight of the liver without the abdominal walls: simple opening of the abdomen seldom induced any descent of the liver. He also found that after opening the abdomen and cutting the suspensory ligament the anterior border of the liver descended about three inches, the right lobe more than the left, while the postericr margin remained fixed. This would necessarily produce anteversion such as occurred in the present case; yet post mortem we were unable to make out any elongation of the suspensory ligament, such as might result from increased traction by loss of the support of the abdominal walls. Winkler ${ }^{7}$ supports the theory of elongation of the suspensory ligament, and Wassilief 'has actually seen such a condition. It must be borne in mind, however, that there is no proof that this ligament is normally tense in the healthy subject. in my case there was no mesohepar, which, according to Hirtz, exists only in Meissner's imagination, and the other ligaments appeared perfectly normal. Fanre ${ }^{9}$ is disposed to regard the coronary ligaments and the connective tissue investment of the inferior rena cava as the true suspensory ligament of the liver; this would harmonise with the clinical condition of our case, the general descent being due to weakness of the coronary and lateral ligaments, the right lobe by reason of its greater weight descending first sind most. Faure attributes the leagthening of the ligaments to a general nutritive defect leading to stretching of the fibrous tissues generaliy, and so causing both flaccidity of the abdoninal walls and weakness of the ligaments. Descent of the liver has been laid to the charge of tight lacing, but this phantom tends to crop up whenever a disorder is specially incident on the female sex. Whatever may have been her habits in the green tree, there was no indication of such a cause in the sere and yellow leaf; moreover, as

St. Bartholomew's Ifospital Reports, 1877.

4 Transastions of Coliege of Physicians of Philadelphia, 1896.

Deutsches Archiv für Klinische Medicin, 1875, Band xiv., Heft 1.

Transactions of the American Assoeiation of Pbysicians, 1895

7 Zur Casuistik und Aetiologie der Waqderlober, Archiv für Gynäkologie, 1372, Band 4, p. 145.

Wiener Medicinische Bläter, 18ع0, No. 30, p. 785

Thèse pour le Dostorat en Médeciue, Paris, 189 ?.
Graham remarks, tight lacing leads to errors of form rather than of position of the liver.

In most of the recorded cases, as in this, the onset of the symptoms has been insidious; sudden onset is usually, but not always, traumatic, and is marked by the familiar symptoms of Eevere biliary colic. There has usually been dull aching pain, worse on exertion; my patient referred her most constant pain to the lower part of the back and between the shoulders, and described it as dragging. Pain and tenderness over the liver only became a prominent feature in the late stages, when the codema present must have exerted a great distending force on the liver. The intense general abdominal pain of the later stages was probably referable to the recent peritonitis, which was found over the spleen. The dragging pain was always worse on exertion, but not completely relieved by recumbency.

The histological characters of the liver are peculiarly definite. The most striking feature is the widespread atrophy of the liver cells; apparently this is not a purely mechanical process, as the atropby is equally marked away from the distended bile-ducts as in their immediate environment. No doubt the degree of œdema manifested ander the micro. scope would bave greatly generalised the pressure, but much of the atrophy is probably due to icteric necrosis. It is surprising that so extensive a cellular atrophy shonld not have led to some degree of secondary connective tissue overgrowth, but such is conspicuonsly absent, only the most delicate capillary network being risible between the residual liver cells. Such a condition would suggest a somewhat rapid atrophy of the true liver cells. The limitation of the increased fibrosis to the bile-ducts is in this case indisputable. Respecting the odema it must be borne in mind that not only was the vis a tergo diminished by the assumed constriction of the portal vein, but likewise a block may have existed ahead from traction on the hepatic vein or the inferior vena cava. It is true that much of the lymph drainage of the substance of the liver passes out at the portal fissure, and may have been involved in the local torsion, but obviously there must have been other channels of efflux patent or jaundice could not have occurred. Weber ${ }^{10}$ surmises that the fibrosis about the bile ducts is due to organisation of scavenger cells that have been attracted to the part by the necrosed liver cells. This can hardly apply to the present case, as the atrophy is uniform and universal, while the fibrosis is strictly localised to the bile.ducts. Weber quotes some experiments of Nasse to show that the effect of Iigature of the hepatio duct is to cause atrophy of the liver cells, and that if the obstruction be removed the liver cells are capable of undergoing some degree of regeneration. Of the former proposition there can be no doubt, but in the present case the persistence of the obstruction precluded a confirmation of the latter.

Wimpole-síreet, $\mathrm{W}$

\section{ADMINISTRATION OF ANAESTHETICS THROUGH A TRACHEAL WOUND.}

BY THOMAS ANNANDALE, M.D., F.R.C.S., F.R S. KDIN, REGIUS PROFESSOR OF CLINICAL SURGERT, EDINBURGH UNIVERSYTY.

IN March, 1887, I published in the Edinburgh Medical Journal a short paper upon Preliminary Tracheotomy as an Aid to Certain Operations. In this communication I described and figured a simple appliance for keeping a patient under the influence of chloroform or ether in connexion with operations which necessitated a previous tracheotomy. Since then I have used this appliance from time to time with success, but having found that the indiarubber tube connected to the tracheotomy tube was some times apt to get twisted at its point of connexion and so interfere wilh respiration, and also that matters conghed up were not readily expelled through the long tabe, I have had my apparatus improved so as to lessen these risks. This modified appliance was recently employed with perfect success in a case of excision of the entire larynx and portion of the trachea together with a large and vascular thyroid tumour, the patient being now quite convalescent.

rhis improved apparatus is as follows:-1. An ordinary fullsized silver tracheotomy tube having its upper end extended

10 Brit. Med. Jour, vol. i., 1896. 